\title{
RADIO TIME SHARING AND THE NEGOTIATION OF LINGUISTIC PLURALISM IN ZAMBIA ${ }^{1}$
}

\author{
Debra Spitulnik
}

\begin{abstract}
The seven (7) main vernacular languages on the Media represent all seventy three (73) tribes found in Zambia (Kapeya 1988: 3).

The problem is, we have been recognized as a language, so why be mistreated? . . It remains that the big two or the big four get most of the time. . . But you can't raise these issues because you may be called a tribalist (Anonymous).
\end{abstract}

\section{Introduction.}

1 mass media construct the communicative space of the nation-state, all of a nation's inguages, dialects, and language varieties, and the speech communities associated with them, are automatically drawn into relations with one another. Some languages and arieties may be dominant with a greater quantity and quality of media products, some may be represented only minimally, and still others may be completely absent, either Jenced or ignored. While there is a growing literature on how such institutional rocesses are bound up with the politics of ethnicity and national identity, the magining' of national communities, and the establishment and maintenance of ominant linguistic practices ${ }^{2}$, it seems to me that three basic issues have remained rgely understudied:

(1) How do various institutional practices differentially value languages (and inguage variants), and which aspects of language in particular become important in he institutional construction of language value?

(2) How do people talk about (and justify or contest) these institutional practices

${ }^{1}$ A much shorter version of this article was presented at the AAA conference, November 23, 1991. ta is drawn from 1988-1990 research at the Zambia National Broadcasting Corporation, which was pported by Fulbright-Hays and NSF fellowships and facilitated by the Institute for African Studies at University of Zambia. I am especially grateful to the numerous ZNBC personnel who generously ve their time and encouragement to this project, and to Susan Philips, Michael Silverstein, Edwin ilmsen, and two anonymous Pragmatics reviewers for their insightful comments on earlier drafts.

${ }^{2}$ See, for example, Anderson (1983), Collins (1988), Fishman (1989), Gal (1989), Silverstein (1987, $\$ 0)$, and Woolard $(1985,1989)$. 
and valuations?

(3) How are (1) and (2) related? How is discourse about language values related to the valuations of language in practice?

This article attempts a preliminary exploration of these issues through a case study of the politics of linguistic pluralism in Zambian radio. Echoing the introductory quotes, we will examine how seven radio languages are made to "represent" 73 ethnic groups, and how certain languages are accorded high status while others are "mistreated." Before turning specifically to the Zambian situation, however, we will elaborate the issues raised above and sketch out their connections to the problem of language ideology as it has been variously defined in recent work.

In some analyses these types of comments and practices - e.g. evaluating some languages as "better" than others or constructing a national scheme of linguistic pluralism - would be considered language ideologies, or evidence of language ideologies. Certainly these phenomena are 'ideological' in the sense that they feed into and are fuelled by relations of power and interest. They are also 'ideological' in the sense that they are tied up with the cultural conceptions (or modes of understanding and evaluation) that characterize any given society. And finally, they are 'ideological' in the sense that languages can represent speech communities, and thus become the focus of political struggles over who counts and is counted in the national arena.

As both Woolard (this volume) and Friedrich (1989) point out, such applications of the term "language ideology" traverse the complex (and often competing) formulations of ideology in social theory, e.g. as shared beliefs, secondary rationalizations, and modes of legitimating power relations. These types can overlap to some degree and may also be differently defined in terms of where ideology resides and how, analytically, it can be distilled. Thus some definitions revolve around distinctions between "explicit" and "implicit" ideology, or the relationship of consciousness and speech to ideologies which are embodied "in practice." But as the applications of the term "ideology" proliferate, it seems to be less and less useful analytically. And if, as Friedrich suggests, "everything" is potentially ideological in the sense that the cultural construction of meaning and value is bound up with relations of power and interest (1989: 300), then the term is only useful in a technical sense within a theoretical framework which specifies what kinds of data count as ideology (i.e. what if not "everything" is ideological), and what kinds of relations of determination exist between these levels of phenomena (e.g. between the ideological and the non-ideological, or between power and culture).

I raise these difficult theoretical issues not so much to take a stance on them, but to clear some ground, and to return to some more basic questions about the kinds of evidence that we use (1) to identify and distill cultural conceptions (and understandings) of language, languages, their speakers, and language use, and (2) to investigate the role of powerful institutions in constructing and maintaining these conceptions (or valuations or 'ideologies'). Rather than looking directly for ideas, or who wins, it seems more productive at least initially to examine such questions of language ideology through the recurrent themes that emerge from a range of types of data (e.g. interviews, political documents, participant-observation, historical changes, 
etc.). Silverstein (1987) and Woolard (1989), for example, locate language valuations in the rhetorical structuring, folk views, and common metaphors, analogies and tropes that dominate certain language policy debates in the United States. While any or all of these discursive modes and moves might be called "language ideologies", neither of the two studies use this cover term, and instead frame the problem of the politics of language value specifically in terms of the production of certain kinds of discourse and commentary.

Following this approach here, I hope to introduce a further dimension to the problem, namely, how one might connect the ways that people talk about the values and roles of languages with broader institutional processes. Thus beyond identifying the common themes and tropes in the spoken battles over language value in Zambia, I attempt to trace out their sources in and resonances with the national discourse on pluralism, the historical emergence of a scheme of language ranking, and the differential valuation of languages in broadcasting practice. And although this essay has opened in a sense with the spoken battles, I begin with the more general processes to establish the historical and political momentum behind the various ways that people talk.

\section{An overview of radio's role in the negotiation of linguistic pluralism.}

Since its inception 51 years ago, radio broadcasting has been one of the most visible and contested arenas of language valuation and national language policy implementation in Zambia. Fundamentally, what underlies the political volatility of language use on radio is that Zambian broadcasting is the primary state institution for representing both national unity and national diversity. Radio is restricted to use only eight of the country's 15 or so languages: English, Bemba, Kaonde, Lozi, Lunda, Luvale, Nyanja, and Tonga. At the same time however, radio is charged with upholding a national philosophy of ethnic egalitarianism (among the nation's "73 tribes") and the obvious aim of political encompassment, as encapsulated in the national motto "One Zambia, One Nation." Collectively, then, the eight radio languages are intended to represent both the nation as a whole and its internal diversity.

In this process Zambian radio operates with two competing visions of the nation's diversity. Radio's use of different languages is structured by both a vision of ethnic egalitarianism in line with nationalist discourse, and a hierarchical ranking of the nation's languages which is linked to the political and demographic inequalities among their speech communities. As we will see in more detail below, Radio Zambia balances these different pluralisms in three basic ways: (1) through a differential allocation of radio airtime which both regulates language equality and gives languages different unequal values, (2) through various modes of establishing evaluations of each of the seven Zambian radio languages vis-a-vis the country's national language English, and (3) by accommodating the interests of 73 ethnic groups within the programming constraints of these seven languages.

While these various valuations of language "in practice" do not directly dictate 
the ways that Zambians talk about the politics of language value, there are strong relations of determination. The discussion below illustrates how certain institutional processes give a fixity and legitimacy to (i.e. naturalize) certain language valuations, but are also at times contested, manipulated, or simply ineffective in producing consensus. A different kind of determination arises from the particular structures and functions specific to an institution in the sense that they may focus on some features of language (e.g. phonology, syntax, code choice) as more critical than others in constructing language value. As radio is a medium defined and structured by time, wavelengths, and sound, it is not surprising that much of the concern over radio language use in multilingual situations such as Zambia has been about the allocation of airtime and channels to different languages and the normative use of "standard" or "non-standard" phonology. ${ }^{3}$

Additionally, there are some modes of evaluating languages which while implicit in broadcasting practice, actually have their sources (or are just as solidly grounded) outside of radio, in national discourse, in labor markets, and in more general understandings about the relations between language, culture, and identity. For example, a major theme in the negotiation of linguistic pluralism in Zambia concerns the way in which "a language" is taken to emblematize a people, an ethnic group, or a political unit. Closely tied to this interpretation of languages as representing collectivities are evaluations of the communicative functions (or domains or topics) that they canonically serve. Using Ferguson's classic formulation of diglossia, this would involve the "specialization of function" of different codes across different speech situations, contexts, and genres (1959: 328). But from the perspective of institutional practices, rather than speaker choice or overall contextual distribution of codes, this "specialization" depends on how the appropriateness of different languages for different functions and topics is legitimated by some regularity of practices. For example in Zambian broadcasting, some languages are constructed as more "intellectually equipped" and others as better suited for "cultural expression" through their exclusive use for certain program types. Significantly, these perceived qualities of languages are entangled with particular assessments of their speakers, e.g. as rural people, urban consumers, "illiterate", "sophisticated", "insignificant", etc., and I would argue that the two modes of evaluation are not really separable. These evaluations do not emanate strictly from radio, however, but are more directly grounded in the overall political economy of languages in the country, as linguistic competence (and membership in certain speech communities) structures access to education, labor markets, and political power.

\footnotetext{
${ }^{3}$ Interest in normative language use also focuses on issues of "non-standard" vocabulary, idioms and syntax, as well as norms of language interaction (e.g. whether broadcasters exhibit proper turn-taking and deference).
} 


\section{Pluralism in national politics.}

\section{The culturalization of ethnicity and the vices of tribalism.}

Turning now to Zambia's national discourse on pluralism, there are 73 officially recognized ethnic groups which are constructed as equally different, i.e. different in the same way, in terms of their presumably harmless, apolitical 'cultural' differences. Amounting to a virtual culturalization of ethnicity, each ethnic group is said to have its own unique traditions, dances, songs, and history, which it is encouraged to preserve and promote for the sake of the youth, tourism, and national identity. National discourse thus attempts to diffuse the political dimensions of ethnicity at the same time that it promotes an image of the state as tolerant of diversity. References to the more volatile differences between ethnic groups, particularly their inequalities in population, political positions, and economic resources, are avoided at all costs. Furthermore, there is no direct discussion of ethnic favoritism or conflict at the national level (except to denounce them), although both significantly structure social relations and politics, and are frequent topics of everyday conversation.

Instead, politicians constantly invoke the national motto "One Zambia, One Nation" as a symbol of a national unity which is predicated on being able to hold together and tolerate ethnic difference. On this note, Zambia is rather exceptional among modern African states as it has experienced almost no violent ethnic conflict, and has prevented any one ethnic group from monopolizing political power. But while claiming to have forged a national unity of "73 tribes united", the Zambian state has always simultaneously attended to the politics of ethnic difference and special interest. Zambia's first and long ruling president Kenneth Kaunda carefully orchestrated a policy of "tribal balancing" in political appointments, and early on articulated what became the general consensus in Zambia's political culture regarding the "deadly vice" of tribalism (Kaunda, 1967: 11). Analogous to racism or sexism, tribalism is understood as discrimination or preference based on ethnic identity. Warnings against "falling victim to tribalism" and denunciations of its divisive, retrogressive, and fundamentally un-Zambian nature pervade political oratory, and were continually raised during one-party rule (1972-1990) in illustrations of what would ensue if a multi-party system were adopted.

In a very curious and complex way, then, Zambia's rhetoric of encompassing nationalism ("One Zambia, One Nation") and its philosophy of ethnic pluralism are mutually reinforcing, but are also in a constant state of tension with the possibility of ideological implosion. The national claim to build unity, fend off tribalism, and also encourage unique ethnic cultures, creates a cautious pluralism within bounds, where diversity always verges on divisiveness, and where attention to difference itself borders on subversion. As we will soon see, this, in a nutshell, describes Radio Zambia's position concerning language diversity as well. 


\section{Democratic vs. hierarchical linguistic pluralism.}

\section{A convergence of language history, policy, and demographics.}

Alongside the national discourse of apolitical ethnic egalitarianism, Zambia has developed a national language policy which also stresses pluralism but ignores difference. This has been accomplished mainly through sanctioning an extraordinarily high number of "official languages" - seven - which are all subordinated to the ethnically neutral "national language", English. The seven official Zambian languages are Bemba, Kaonde, Lozi, Lunda, Luvale, Nyanja, and Tonga, and they are the only Zambian languages used in broadcasting, schools, and government publications. English, the former colonial language, is the language of government, higher education, and international communication. The choice of which seven, out of a total of between 15 and 20 distinct languages and perhaps as many as 50 different dialects ${ }^{4}$, was fairly well determined before independence by the convergence of several processes: colonial language policy (especially in broadcasting and education), missionary work, and labor migration patterns which established Bemba and Nyanja as the colony's two urban lingua francas. ${ }^{5}$

Crucially, English, Bemba, and Nyanja were the first languages of Northern Rhodesian broadcasting, which started in 1941 as a World War II information service. Following the war, Lozi and Tonga were added as the service expanded. According to Harry Franklin, the Northern Rhodesian Director of Information, nearly everyone understood these four "main 'root' languages of the country", and thus it was unnecessary to add more languages despite several requests to do so (1950: 16). Significantly, Franklin saw radio as having a key role in helping to standardize languages and promote the dominance of some over others:

Africa's babel of tongues is one of the main causes of its people's backwardness, and we hope eventually to reduce languages broadcast rather than to increase them, and so to play a part in the eventual development of one African tongue ... and still more remotely, in the universal use of English (1950: 16).

Over time, the selection and dominance of the four languages became mutually reinforcing, and this arrangement was extremely convenient administratively, as their geographic distribution virtually aligned with the four compass points North (Bemba), South (Tonga), East (Nyanja), and West (Lozi), which defined the major provinces of

${ }^{4}$ The most comprehensive studies suggest that there are 15 to 20 distinct (non-mutually intelligible) languages in Zambia, but many of the 73 ethnic groups claim to speak their own unique language (Kashoki, 1978). Behind this is the complex, political issue of defining "a languagen "vs. "a dialect", which is further compounded by the limited comparative data on language variation in the country. Cf. Kashoki and Mann (1978) and Lehmann (1978).

${ }^{5}$ Historical data is drawn mainly from Kashoki (1978), Roberts (1976), and Mytton (1978). 
the colony. ${ }^{6}$ In 1954, however, the two Northwestern Province languages Lunda and Luvale were added to broadcasting (no single language was prominent in the province), and at Zambia's independence in 1964, an additional Northwestern Province language, Kaonde, was included.

The contemporary linguistic situation in Zambia is in large part a legacy of these trends in colonial administration, and the related trends in ethnic politics. In effect, the use of numerous Zambian languages in early radio broadcasting did not help to reduce "the African Babel", but helped to permanently establish some of the basic terms in which ethnolinguistic diversity is structured and experienced in Zambian society. Different languages became associated with different prestige values and domains of use in the national context, primarily through the "uneven development" of the ethnic groups speaking them ${ }^{7}$ and their concurrent unequal valuation in broadcasting. The high status and widespread use of Bemba and Nyanja, "the big two", grew as their value in the urban labor markets became established, and this was accompanied by higher proportions of radio airtime for them. These two, along with Lozi and Tonga came to be known as "the big four" as their first language speakers emerged as the major ethnic and regional power blocks in national politics (cf. Molteno 1974). For most of broadcasting history, Lozi and Tonga have had slightly lower proportions of airtime than Bemba and Nyanja, but more than the three Northwestern languages which are associated with much smaller populations and ethnic power bases. The use of these three in contemporary Zambia is fairly limited to their own mother-tongue populations (e.g. $7 \%$ of all Zambians speak Kaonde, while $3 \%$ of the country is ethnically Kaonde). By contrast, the Bemba and Nyanja languages far outreach their ethnic populations (19\% and $16 \%$ ) and are spoken by $56 \%$ and $42 \%$ of all Zambians, respectively (Kashoki, 1978). What obtains then in Zambia is not a situation of democratic linguistic pluralism in line with the national discourse of ethnic egalitarianism. All languages (or even just the seven chosen languages) are not equally valued, rather, they are hierarchically ranked (Figure 1). This language ranking is both a historical product of colonial administration and ethnic politics, and a partial diagram of the demographic and status inequalities among speech communities.

\footnotetext{
${ }^{6}$ The contemporary discourse of regionalism, which flows directly from these relations of power established during the colonial period, is one of the major tropes of ethnic and language politics in Zambia, and deserves much more treatment than is possible here (cf. Mitchell 1956: 28-30 and van Binsbergen 1985: 203).

${ }^{7}$ The historical connections between colonial language policy and the construction of ethnicity in Zambia remain to be fully investigated. But see Mitchell (1956) and van Binsbergen (1985) on how disparities in missionization, rural development, and access to education and labor markets were instrumental in the articulation of ethnic difference and affiliation during the colonial period.
} 
Figure 1. Hierarchical linguistic pluralism in Zambia.

colonial language

international language

urban lingua francas

languages of dominant ethnic groups

Northwestern Province languages
English

Bemba, Nyanja<smiles>[AlH2]</smiles>

Bemba, Nyanja, Lozi, Tonga

government, higher education, $\mathrm{TV}$, radio, daily newspapers

"national language"

\section{The politics of language value in contemporary radio.}

\section{Partitioning the linguistic universe.}

The politics of language value, and especially the grounding of this scheme of hierarchical linguistic pluralism, occur most prominently in four domains in which the Zambian linguistic universe is essentially partitioned through broadcasting practice: the radio channel, airtime, administrative resources, and program content. In the following, we will examine how the very way that the medium of radio is carved up establishes basic structural contrasts which can become focal points for the construction (and contestation) of language value.

Since the early days of broadcasting in Zambia the airwaves have been carefully divided up among different languages, and concurrently distinct administrative units have been assigned responsibility for the output in each of the different languages. Most pronounced has been the segregation of English vs. Zambian languages - in terms of both airwaves and program types - and one of the key issues of attention and contestation has been which Zambian languages are treated more (or less) like English, which clearly occupies the privileged position in the language hierarchy. Table 1 illustrates the special status of English in terms of ZNBC's radio channels. ${ }^{8}$ Not only are there currently more than twice as many hours for English as for all Zambian languages combined, but the two English channels also monopolize the more

8 While technically "channel" denotes a broadcast frequency, it ZNBC's term for a distinct programming schedule. ZNBC runs the country's only broadcasting operations: one television and four radio channels. Radio 3 is an external service for Southern Africa. The three domestic radio channels are all centrally run from the capital Lusaka and have simultaneous national transmission on their various frequencies. 
prestigious FM frequencies. Furthermore, up until 1991, Zambian television broadcast exclusively in English, and presently it carries only one hour of Zambian languages per day. The names "Radio 1" and "Radio 2" were introduced in 1989 with the creation of "Radio 4", and were preceded by five other pairs of labels. The various alterations in both the channels' names and languages reveal a constant attention to the politics of language value, and illustrate the ongoing practices which are necessary to sustain and justify certain valuations; we consider them in detail below. ${ }^{9}$

Table 1. ZNBC radio operations, 1990.

\begin{tabular}{|c|c|c|c|c|}
\hline & Hours & Frequencies & Languages $\%$ & $\%$ of total radio broadcast time \\
\hline Radio 1 & $04.50-24.05$ & $\overline{S W, M W}$ & $\overline{7 \text { Zambian } \operatorname{lgs}}$ & $31 \%$ \\
\hline Radio 2 & $04.50-24.05$ & SW, MW, FM & English & $31 \%$ \\
\hline Radio 4 & Contin. $24 \mathrm{hrs}$ & FM stereo & English & $38 \%$ \\
\hline
\end{tabular}

From the late 1940s up to Zambian independence in 1964, broadcasting operations for Africans and Europeans were separate. The "African Service" emanated from Lusaka (the Northern Rhodesian capital) and the "English Service" came from Salisbury (the Southern Rhodesian capital). The African Service carried a few programs in English for Africans, but most English language programs were produced in the Southern Rhodesian studios. Zambian broadcasting inherited this operational imbalance and language segregation at independence, and out of this situation the "Vernacular Service" (with 7 Zambian languages) and the "National Service" (with English only) were created in 1964. Racial overtones were thus eliminated with both the rejection of the label "African" and the revaluing of English as something "National", i.e. rightfully belonging to the newly independent nation-state and not any one race. But even with these new labels, the comparative scopes of the two channels and their implications for language valuations remained fundamentally the same: Zambian languages were still segregated from English, which stood apart as the language of wider, national, and more modern communication.

Oppositions to these distinctions erupted during the two years following independence as the channels' names were changed three more times, and controversies continued as the allocation of languages to each channel was altered as well. In 1965, for example, the National Service was relabeled "the English Service", in an attempt to dispel any implication that the "vernacular" languages of its counterpart were not also 'national'. The implication endured, however, and in 1966 the Vernacular and English Services were renamed "Home" and "General" thus even further accentuating differences in scope. The Home Service, as something 'not-general', carried connotations of being specific, local, and even narrow. Resonating with

${ }^{9}$ Sources: Handbook to the Federation of Rhodesia and Nyasaland, 1960 (Salisbury: Government Printer) p.552. A Handbook to the Republic of Zambia, c. 1965 (Lusaka: Government Printer) p.105-7. Nshila, nos. 183-236 (January 29, 1965 - February 10, 1967). 
Zambian idioms of ethnic origin and rootedness, the word "home" also signalled that the "vernacular" broadcasts were for rural and ethnic-based audiences, and tapped into their essential identities, e.g.

"[ZNBC realizes] the importance of a vernacular language as being the [sic] most andproper communicator and a true identifier of man's belonging. . . (Kapeya 1988: 2)."

Even after the Home Service was relabelled "Radio 1" in 1989, ZNBC broadcasters continued to draw upon the themes of home and belonging in promoting the channel, e.g. in Bemba slogans such as "Kumwesu kwaliwama", 'At home (our place), it's nice'.

The General Service, on the other hand, as something 'not-home', did not belong to anyone in particular. Associated with wider (more general) spheres of communication, and seemingly dissociated from locality, ethnicity, and special interest, the General Service used the one language which symbolizes the transcendence of such boundaries, English. This situation did not remain for long, however, and soon several controversies erupted over which languages could rightfully share time with English on the General Service. In early 1966 "the big four" (Bemba, Nyanja, Lozi, Tonga) were added with the rationale that their audiences were larger and therefore they needed more hours. But a year later, Lozi and Tonga were removed, leaving "the big two", which remained on the General Service with English for nearly 20 years, thus acknowledging the wider scope of the lingua francas and the possibility that they did not necessarily belong to any one people.

The problem, was however, that while Bemba and Nyanja are widely used by people of all ethnicities, their links to specific ethnic constituencies remains a continually invocable reason for limiting their use at the national level. Bemba and Nyanja are simply not 'general' like English, and in selecting them over others one is open to being "called a tribalist", as this complaint to the Ministry of Information and Broadcasting implies:

"Some languages have more hours than others [and] only two of the seven languages are on the General Service ... [This is] unfair as far as the national motto of "One Zambia, One Nation" is concerned. (Letter from Northwestern Province, received 13 August 1981, ZBS/101/1/5)."

Since the national motto "One Zambia, One Nation" is about uniting an ethnically plural society, to these letter writers unity was violated by separating out two Zambian languages to share a channel with English. As the pressures increased for the General Service to "include everybody", the other five languages were added in the mid 1980's but equal time was not granted. The situation was then dramatically reversed in 1988. All Zambian languages were removed from the General Service, and it resumed its much earlier status as English only. Significantly, this 'all or nothing' decision evoked both praise and criticism, essentially drawing from two competing visions of pluralism.

On the one hand there was the danger of having too much pluralism, i.e. a pluralism verging on divisiveness and confusion ("the African Babel"), with the possibility of contamination especially when it came to mixing on a com-mon channel with English. One listener, for example, lauded the removal of Zambian languages and expressed the 
"sincere hope that these changes will help bring back to life the [sic] turnished image of the general service ..." (Times of Zambia, October 16, 1988, p.4).

Others felt that the presence of Zambian languages on a channel with English was too disruptive, or that only English was necessary for General Service programs such as health, farming, and educational broadcasts. The colonial bifurcation of English vs. all other languages thus remained with lingering connotations of English as the sole language of prestige and progress.

On the other hand, there was the view of pluralism as positive and necessary for national communication and the promotion of Zambian culture. Several listeners strongly opposed the removal of all Zambian languages from the General Service, complaining for example that "English has the lion's share" while Zambian languages were "deprived of adequate air time" (Times of Zambia October 1988). One commented sarcastically, "I suppose that is the penalty they get for being Zambian languages" (Times of Zambia October 11, 1988 p.2).

The problem of singling out two languages surfaced again in 1989 when ZNBC introduced Radio 4, a 24 hour FM stereo channel designed to carry a mixture of pop music programming and commercial advertising. ${ }^{10}$ Initially, some ZNBC staff thought Radio 4 would use all eight languages, but from the outset it was English only. This was justified by claims that advertisers all preferred English, and that listeners who spoke only "the home languages" had no buying power and would therefore not be good audiences for a channel that was to be supported by advertising revenue. Other staff noted that since FM radio covered only urban areas, there was no need for the vernaculars which were for villagers. But despite all of these seemingly objective appeals to external factors, none of these claims were supported by market research, and in fact they ran contrary to the well known fact at ZNBC that urban people do listen to Bemba and Nyanja programs.

So why weren't the two lingua francas added to the new urban-based channel? Over two-thirds of all Zambians speak at least one of these languages, and nearly half of all Zambians live in urban areas. Certainly the listeners were there. And regarding business interest, one senior executive acknowledged that

"Bemba and Nyanja are the only two languages that bring any money [on Radio 1]. That's why they are slotted at lunch time, and they have commercial programs ... The sponsors shun some of these other [languages]."

ZNBC executives knew that the two lingua francas could have been successful on Radio 4 , but the choice was political. In terms of ethnolinguistic impartiality, the issue paralleled that of the embattled General Service languages: either have all Zambian languages on the new channel, or none at all. Even if Bemba and Nyanja reach wider

${ }^{10}$ Radio Zambia has had commercial advertising since the 1960 s, but Radio 4 was created to increase advertising income. As ZNBC is a parastatal body with corporate status, it can generate and invest its own revenues, but it is substantially controlled by the Ministry of Information. Radio 4 is thus not a "commercial" (privately owned) radio channel in the Western sense, and outside commercial interests have had only minimal impact in shaping programming decisions. 
audiences, their connections to specific ethnic groups lurks in the background of any decision over their use. With the additional aim of styling Radio 4 after Western FM pop radio, the exclusive use of English not only dispelled controversies over "tribalism", but was a 'natural' consequence of its status as the modern, international language.

\section{The linguistic division of labor.}

The "penalty" that Zambian languages "get for being Zambian languages" thus extends beyond the allocation of airtime and channels into a virtual institutionalization of what counts as their appropriate program content. English has long been established as the language of international news, current affairs discussions, and the majority of scientific and formal education programs, while Zambian languages carry mostly cultural and development programs. ${ }^{11}$ Ethnolinguistic pluralism is therefore contained not only within one channel, but also in terms of certain topics, and specifically through an equal subordination under English in this linguistic division of labor.

Most prominent is the construction of language equality through linguistic uniformity. To take one example, the same English script is used to prepare the daily Zambian language newscasts, so the news in each of the seven languages is identical in format and content. The master text is extracted from the script of the preceding English language "Main News", but it is half the length, with the international items usually omitted. In this equal subordination under English, Zambian languages are often equated with the rural folk, even though nearly half of all Zambians and over three-quarters of all radio listeners live in urban areas. Thus similar to the Radio 4 case above, news staff claim to be just following the norms "out there" when they explain that the "sophistication" of the Radio 1 audience differs from the English language audience, and that a five minute excerpt from the ten minute English news is adequate for them. As one senior news editor elaborated, "We wouldn't give an item on the SALT talks in Geneva. If they could understand that, they could listen in English." Another said,

"You don't pick something in Saigon or China, because you may be reaching illiterates . . . There are complicated issues which wouldn't even make sense to them."

There was no audience research, however, to substantiate these views, and in a sense, the ability of newscasting to widen people's horizons was short-circuited by the assumption that their intelligence was unalterably limited. Many Zambians who know little or no English do have an interest in world events, and would like more international news in their own languages.

In apparent contrast to the news editors' statements, ZNBC administrators point to the use of seven languages as examples of broadcasting's dedication to the national

11 The functional segregation of languages is even more severe in the education system. English is the medium of instruction after Grade 3, and Zambian languages are taught as subjects, with traditional culture as typical content. 
policy of "taking things to the people." But what is being taken, and who are these people? Most informational programs in Zambian languages are on national politics and development topics such as farming and health, and I would argue their audiences are in a sense "the imagined others" for the highly cosmopolitan English speaking broadcasting elite. The audiences thought of as "illiterates" are bascially those who have not reached a certain level of formal education, in English, and to some media elite this precludes an ability to comprehend or share the same world views.

Not only does radio's institutionalization of limited program content for Zambian languages perpetuate this perceived divide, but the use of English master scripts for these informational programs further regulates linguistic uniformity (or egalitarianism), and constructs English's high value as the scientific and factual language. By contrast, most independently scripted programs in Zambian languages adhere to the politically acceptable expressions of ethnic diversity - that is, traditional music, storytelling, and cultural topics. Through these broadcasting practices, then, the seven vernaculars are valued as equally transparent vehicles for communicating the same information to ethnically diverse people, and as equally particularistic codes for gaining access to different ethnic cultures. ${ }^{12}$

\section{Time sharing on Radio 1: Regulating language sameness and difference.}

As indicated above, the allocation of radio airtime itself has emerged as one of the key measurements of linguistic equity: not all languages have the same amounts (and types) of air-time, and thus the promotion of a simple linguistic egalitarianism as one would expect from the national philosophy is far from clear. Instead, Radio Zambia has developed a complex schedule which simultaneously regulates language equality and gives languages different, unequal values. With such a dynamic of language valuation, radio both upholds a vision of balanced pluralism and operates with its seeming contradiction, a scheme of hierarchical linguistic pluralism.

Significantly, the partitioning of radio airtime among seven Zambian languages and their ability to represent 73 ethnic groups is limited to one radio channel. Figure 2 illustrates how Radio 1's schedule carefully staggers the seven Zambian radio languages across the different days and times of the week, and this establishes a basic image of one national pie that is getting divided up. As people talk about this radio time sharing, various discourses of ethnolinguistic democracy are invoked which play into and seize upon these structural contrasts.

\footnotetext{
${ }^{12}$ If Zambian languages are cultural reservoirs then English is an economic reservoir, or at least the avenue for tapping into economic resources. This issue needs more extensive treatment in terms of the overall political economy of languages and class dynamics in the country, but briefly its significance in radio's negotiation of linguistic pluralism lies in English's exclusive use as the neutral language of translation and encompassment. The material here suggests that radio's (and the media elites') role in constructing this seemingly natural neutrality and transcendence of English cannot be understated.
} 
Figure 2. Time allocation of Radio 1 languages (1990). ${ }^{13}$

\begin{tabular}{||l|l|l|l|l|l|l|l||}
\hline \hline Time & Mon & Tues & Wed & Thurs & Fri & Sat & Sun \\
\hline $04.50-08.00$ & $\mathrm{~B}$ & $\mathrm{~T}$ & $\mathrm{Ln} / \mathrm{Lv}$ & $\mathrm{Lz}$ & $\mathrm{K}$ & $\mathrm{N}$ & $\mathrm{B}$ \\
\hline $08.00-10.00$ & $\mathrm{Lz}$ & $\mathrm{K}$ & $\mathrm{T}$ & $\mathrm{Lv}$ & $\mathrm{T}$ & $\mathrm{Ln}$ & $\mathrm{B}$ \\
\hline $10.00-12.00$ & $\mathrm{~T}$ & $\mathrm{Lv}$ & $\mathrm{Lz}$ & $\mathrm{T}$ & $\mathrm{Ln}$ & $\mathrm{Lz}$ & $\mathrm{T}$ \\
\hline $12.00-14.00$ & $\mathrm{~N}$ & $\mathrm{~B}$ & $\mathrm{~N}$ & $\mathrm{~B}$ & $\mathrm{~N}$ & $\mathrm{~B}$ & $\mathrm{~N}$ \\
\hline $14.00-16.00$ & $\mathrm{~T}$ & $\mathrm{Ln} / \mathrm{Lv}$ & $\mathrm{Lz}$ & $\mathrm{Lz}$ & $\mathrm{K}$ & $\mathrm{N}$ & $\mathrm{Lz}$ \\
\hline $16.00-18.00$ & $\mathrm{Lz}$ & $\mathrm{K}$ & $\mathrm{T}$ & $\mathrm{Ln}$ & $\mathrm{Lz}$ & $\mathrm{B}$ & $\mathrm{N}$ \\
\hline $18: 00-20.00$ & $\mathrm{~T}$ & $\mathrm{Lz}$ & $\mathrm{Ln}$ & $\mathrm{K}$ & $\mathrm{Lv}$ & $\mathrm{Lv}$ & $\mathrm{T}$ \\
\hline $20.00-24.05$ & $\mathrm{Lz}$ & $\mathrm{N}$ & $\mathrm{B}$ & $\mathrm{N}$ & $\mathrm{B}$ & $\mathrm{T}$ & $\mathrm{B}$ \\
\hline
\end{tabular}

[B Bemba; K Kaonde; Ln Lunda; Lv Luvale; Lz Lozi; N Nyanja; T Tonga]

Below, we see that the national motto "One Zambia, One Nation" becomes a dictum of democracy, i.e. equal representation for all, which then feeds into various modes of measuring language "equality" and "inequality." The middle term in this equation is the essentialist notion that a language is a "true identifier" of a people, thus: if languages represent people, then equal representation for everyone in radio will occur through equal distribution of radio's resources (airtime, programs, staff, etc.) across these different languages. One problem which emerges however, is that if languages do emblematize people, how are 73 different peoples represented by only seven languages? This section closes with an illustration of how ZNBC handles such difficult cases.

In one sense the schedule in Figure 2 presents a picture of distributional equality, where no particular language seems privileged over others. Each day a different language opens the station, no language dominates any large time blocks, and across the weekly cycle, every time slot is shared by two or more languages. A similar construction of distributional equality occurs in the Radio 1 news schedule, where a sequence of back-to-back newscasts in each of the seven languages is broadcast three times daily, starting at $6.00,12.20$, and 17.20 . Within each of these three news periods the newscasts are identical in format and content, but the ordering of languages differs at different times of the day, thus in effect no single language always gets first place at news time.

13 Based on Zambia National Broadcasting Corporation Radio One Programme Schedule, First Quarter 1990. 
At the same time, however, there are great disparities in the quantity and quality of airtime allocated to each language, and this is summarized in Table 2.

Table 2. Radio time sharing on Radio $1 .^{14}$

\begin{tabular}{|c|c|c|c|c|c|c|}
\hline & $\begin{array}{l}\% \\
\text { Zambians } \\
\text { speaking } \\
\text { language }\end{array}$ & $\begin{array}{l}\% \\
\text { Radio } 1 \\
\text { airtime }\end{array}$ & $\begin{array}{l}\text { Days } \\
\text { broadcast }\end{array}$ & $\begin{array}{l}\text { Weekend } \\
\text { hours } \\
\text { PEAK }\end{array}$ & 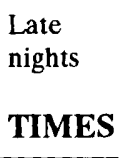 & $\begin{array}{l}\text { Lunch } \\
\text { slots }\end{array}$ \\
\hline Bemba & $56 \%$ & $19 \%$ & daily & 11 & WFSu & TuThSa \\
\hline Nyanja & 42 & 15 & daily & 7 & TuTh & MWFSu \\
\hline Tonga & 23 & 19 & daily & 8 & $\mathrm{Sa}$ & \\
\hline Lozi & 17 & 18 & daily & 4 & $\mathbf{M}$ & \\
\hline Luvale & 8 & 9 & Tu-Sa & 2 & & \\
\hline Kaonde & 7 & 8 & TuThF & 0 & & \\
\hline Lunda & 5 & 8 & Tu-Sa & 2 & & \\
\hline
\end{tabular}

"The big four" have roughly the same amount of airtime, while the three Northwestern Province languages have much less, and do not occur every day, except in newscasts. In terms of measurable hours then there are two tiers - Bemba, Nyanja, Tonga, and Lozi on one level, ranked above Luvale, Kaonde, and Lunda. The high valuation and demographic dominance of Bemba and Nyanja over the other five languages are reflected more in the allocation of peak times, and other forms of institutional favoritism. The two lingua francas have the most late night slots, numerous weekend programs, and the daily lunchtime slots, all of which attract high advertising volume and also correspond with the typical urban laborer's off-work schedule.

The most pervasive theme in both listeners' and broadcasting personnel's discourse about these language valuations is that radio languages represent homogeneous and relatively monolingual speech communities, i.e. ethnic groups. Radio's elaborate partitioning of its universe of addressees at the most general level, as separate but equal speech communities based on language, draws from and feeds into this essentialist view. Thus, while management statements say that "the seven (7) main vernacular languages on the Media represent all seventy three (73) tribes found in Zambia" (Kapeya, 1988: 3), some people simply do not feel represented; they want their piece of the national pie. Many such complaints, as we have already seen, allude to the national motto "One Zambia, One Nation" in making demands for a linguistic

\footnotetext{
${ }^{14}$ Column 1 is based on Kashoki 1978: 39. Other tabulations are based on Figure 2.
} 
democracy. While this motto signifies a vision of equal inclusion, the closely related nationalist slogan "One Man, One Vote" has become a major trope for measuring equal representation, as in this letter to Radio Zambia:

"If we are all Zambians, then we should all get the same privileges. Kaonde should be on the radio for the same amount of time as the other languages. Equal hours for each tribe." (Mytton, 1978: 217.)

Building on the view that one language is "a true identifier" of one people, a whole series of one-to-one correspondences or distributional tropes have thus emerged as assessments of ethnolinguistic equity: one language, one people, one culture; equal hours for every language, etc.

In this ongoing debate over the three Northwestern languages, egalitarianism is also measured in terms of another kind of one-to-one correspondence, that of regional distribution. Some broadcasters and listeners say for example that the Northwestern Province is unduly favored with three radio languages, while the five remaining languages are made to cover the eight other provinces. According to this view, some provinces are actually shortchanged by having no unique radio language of their own, or by having their other languages go unrepresented. But Northwesterners see it differently. To them the criterion of impartiality is not one language per province, but equal hours per language, as this broadcaster explained in 1989:

"The problem is, we have been recognized as a language, so why be mistreated? . . It remains that the big two or the big four get most of the time. . But you can't raise these issues because you may be called a tribalist."

During 1989, ZNBC's concern over such growing sentiments was considerable. Originally Radio 1 had been divided into five different departments: Bemba Section, Lozi Section, Nyanja Section, Tonga Section, and Northwestern Section. This bureaucratic division in itself clearly marked the status of "the big four" as against the others, and ZNBC's response was to administratively repartition this linguistic universe. The Northwestern Section was split into three distinct language units (the Kaonde Section, the Lunda Section, and the Luvale Section), and each was allocated the same number of employees as the other four sections. An administrative analog of linguistic egalitarianism was thus created: one language, one section. Radio time was not changed however.

Other voices of contestation come from Zambians whose first languages are not any of the seven national languages (Mytton 1974, 1978). While national statistics suggest that such people comprise roughly $40 \%$ of the total population, multilingualism is extremely high and in actuality less than $5 \%$ of all Zambians do not understand any of the seven national languages (Kashoki, 1978: 19-21, 38-9). Still, periodic demands for recognition are common, as this letter from a Nkoya listener illustrates:

"Lozi isn't representative of Nkoya, so we should have our own broadcasts. . . We won't accept a situation of being considered as a sub-group of Lozi!" (received 7/89, ZNBC)

The executive handling this said he would check into the government policy to determine if Nkoya was "a language or just a dialect," and presumably this would decide 
whether the Nkoya people could be considered "a sub-group" of the neighboring Lozi people. In the difficult conflation of 73 into 7, ZNBC thus attempts to dispel the essentialist idea that one language represents one ethnic group. In a similar vein, some Zambians invoke this 'language' vs. 'dialect' argument in asserting that there are no more than 6 or 7 Zambian 'languages' in the country, and that some radio languages can be removed without sacrificing comprehension. A corollary emerges here from the earlier theme 'a language equals a people': 'a dialect equals a sub-group'. While the former have real status, the latter are insignificant. One Zambian explained for example that the Northwestern languages are more like dialects of Bemba:

"There are these small languages, what are they, Lunda, Luvale, and Kaonde. No one will argue that they can't use Bemba in the Northwestern Province. Bemba, Nyanja, Tonga, and Lozi would be enough."

But as the Nkoya letter above makes clear, for some the issue is not about comprehensibility but representation. According to the last national survey, radio language comprehension was extremely high across the Zambian population, with the mean number of radio languages listened to overall at 2.9 (Mytton 1974: 26). Indeed, Radio Zambia audiences are not as fragmented as the schedules would suggest, due to the high degree of multilingualism in the country. Many people listen to Radio 1 throughout the whole day, and others tune in selectively to programs in several different languages. To some degree then what listeners do is orthogonal to all of this concern over radio time sharing.

Comprehension is not really the point, however, if languages are viewed as emblems of autonomous ethnic groups: to be excluded from radio is tantamount to being a "sub-group", encompassed by one of the selected seven. To get around this problem of representation, ZNBC has pursued other avenues for allowing linguistic diversity to emerge in its programming. For example, in the Nkoya case above, the ZNBC executive said he would insure that some Nkoya songs were played during the Lozi time slots. Thus consonant with the linguistic division of labor discussed earlier, cries for representation are met by the inclusion of cultural material. While the time blocks and named radio languages themselves cannot be tinkered with, small glimmers of linguistic diversity greater than the chosen seven can occur on the airwaves, but they are of the safe cultural kind.

\section{Conclusions.}

In conclusion, I would like to briefly consider how extensive and effective Radio Zambia is in negotiating two kinds of linguistic pluralism, and then return to the initial questions of how to characterize "language ideology." Zambian radio has been faced with the immensely complex task of reconciling a national philosophy of egalitarianism with a fairly rigid linguistic hierarchy grounded in the demographics of its audiences and the long history of differential language valuation in the country. Since the two pluralisms are fundamentally opposed and never fully resolvable, as we have seen, 
apparent inconsistencies in broadcasting practice can be seized upon as focal points for contestation, especially by those whose languages are excluded or used only minimally. Even so, it is to Radio Zambia's credit that it has supported such a high number of languages within the economic and physical constraints of one broadcasting operation. The only drawback, it seems, is that in its response to the dominant interpretations of pluralism in national politics - where diversity is seen to verge on divisiveness and acts of recognizing difference are potentially "tribalistic" - Zambian broadcasting's extensive promotion of English has weakened its ability to adequately provide for all of its listeners in the seven Zambian languages. In this sense, pluralism is not really negotiated at all, it is muted.

It is tempting to relate this handling of linguistic pluralism to the wider issues of national integration and the diffusion of ethnic conflict in the country, but these processes far outreach the modes of language valuation discussed here, and are more dependent on factors such as economic stability and political representation. More narrowly however, Radio Zambia's role and effectiveness in establishing and reproducing language values is extensive and begins during the colonial period, as we have seen. In particular, radio's differential allocation of resources (e.g. channels, airtime, staff, and program types) among the eight radio languages is very closely linked to the construction of social inequalities among the speakers of these languages (as well as others who do not feel "represented" by radio languages), and this deserves more detailed study.

The approach here, however, has not been so much to assess the role of a powerful institution in producing a net linguistic effect, but rather to trace out how radio's negotiation of linguistic pluralism is structured (and understood) in terms of various historical processes, political discourses, and cultural understandings of the relation between languages and peoples. If these processes are mutually determining and complexly entangled over a 51 year history, on which side of the equation does one locate "language ideology"? One might call the language valuations that emerge through the dynamics of broadcasting "language ideologies which are embodied in practice", while the political discourses and cultural understandings (as evidenced in verbal data) might be termed "explicit language ideologies." But basically this implicit/explicit divide is just a shorthand for the different kinds of data used to distill "ideologies." As we have seen, both schedules and talk about schedules establish and construct interconnected language valuations. Invariably these are tied up with relations of power and interest, in terms of both the national politics of representation and broadcasters' perpetuation of their elite distinctions. It has been suggested here that to call all of these valuations, interests, discourse modes, and cultural understandings "language ideologies" conflates several social, cultural, and linguistic processes under one cover term, and hopefully this case study has sketched out some avenues for investigating their complexity. 


\section{References}

Anderson, Benedict (1983) Imagined communities: Reflections on the origin and spread of nationalism. London: Verso.

Binsbergen, Wim van (1985) "From tribe to ethnicity in Western Zambia: The unit of study as an ideological problem." In W. van Binsbergen and P. Geschiere (eds.), Old modes of production and capitalist encroachment. London: KPI, p.181-233.

Collins, James (1988) "Hegemonic practice: Literacy and standard language in public education. "Working papers and proceedings of the Center for Psychosocial Studies, no. 21. Chicago: Center for Psychosocial Studies.

Ferguson, Charles A. (1959) "Diglossia." Word 15: 325-40.

Fishman, Joshua A. (1989) Language and ethnicity in minority sociolinguistic perspective. Philadelphia: Multilingual Matters.

Franklin, Harry (1950) Report on 'the saucepan special': The poor man's radio for rural populations. Lusaka: Government Printer.

Friedrich, Paul (1989) "Language, ideology, and political economy." American anthropologist 91: 295-312.

Gal, Susan (1989) "Language and political economy." Annual review of anthropology 18: 345-67.

Kapeya, Mwansa (1988) "The use of vernacular languages in broadcasting." Paper presented at a broadcasting seminar in Maputo, Mozambique.

Kashoki, Mubanga E. (1978) "The language situation in Zambia." In S. Ohannessian and M. E. Kashoki (eds.), p.9-46.

Kashoki, Mubanga E. and Michael Mann (1978) "A general sketch of the Bantu languages of Zambia." In S. Ohannessian and M. E. Kashoki (eds.), p.47-100.

Kaunda, Kenneth D. (1967) Humanism in Zambia and a guide to its implementation, part 1. Lusaka: Government Printer.

Lehmann, D. A. (1978) "Languages of the Kafue basin: Introductory notes." In S. Ohannessian and M. E. Kashoki (eds.), p.101-20.

Mitchell, J. Clyde (1956) The kalela dance. Rhodes-Livingstone Papers, no. 27. Manchester: Manchester University Press.

Molteno, Robert (1974) "Cleavage and conflict in Zambian politics: A study in sectionalism." In W. Tordoff (ed.), Politics in Zambia. Berkeley: University of California Press, p.62-106.

Mytton, Graham (1974) Listening, looking, and learning: Report on a national mass media audience survey in Zambia (1970-73). Lusaka: Institute for African Studies.

Mytton, Graham (1978) "Language and the media in Zambia." In S. Ohannessian and M. E. Kashoki (eds.), p.207-27. 
Ohannessian, Sirarpi and Mubanga E. Kashoki (eds.) (1978) Language in Zambia. London: International African Institute.

Roberts, Andrew (1976) A history of Zambia. New York: Africana.

Silverstein, Michael (1987) "Monoglot 'standard' in America." Working papers and proceedings of the Center for Psychosocial Studies, no. 13. Chicago: Center for Psychosocial Studies.

Silverstein, Michael (1990) "The skin of our teeth: Registers, poetics, and the First Amendment." Paper presented at the American Anthropological Association annual meeting, New Orleans.

Woolard, Kathryn A. (1985) "Language variation and cultural hegemony: Toward an integration of sociolinguistic and social theory." American ethnologist 12: 738-48.

Woolard, Kathryn A. (1989) "Sentences in the language prison: The rhetorical structuring of an American language policy debate." American ethnologist 16: 268-78. 